\title{
Inhibition of Osteoclast-like Cell Formation by Bisphosphonates in Long-term Cultures of Human Bone Marrow
}

\author{
D. E. Hughes, B. R. MacDonald, R. G. G. Russell, and M. Gowen \\ Department of Human Metabolism and Clinical Biochemistry, University of Sheffield Medical School, \\ Sheffield S10 2RX, United Kingdom
}

\begin{abstract}
Bisphosphonates inhibit bone resorption in vivo and in vitro by unknown mechanisms. The effect of bisphosphonates on the formation of osteoclasts from their mononuclear hematopoietic precursors was investigated using human long-term marrow cultures in which multinucleated cells form that express most of the known features of the osteoclast phenotype (e.g., bone resorption, tartrate-resistant acid phosphatase, calcitonin responsiveness, and reactivity with specific MAbs). The five bisphosphonates that were tested strongly inhibited 1,25-dihydroxyvitamin $D_{3}$-stimulated formation of these cells with the same relative potencies as they inhibit bone resorption in vivo. Two representative compounds (3-amino-1-hydroxypropylidene-1,1-bisphosphonate and dichloromethylene bisphosphonate) failed to inhibit the proliferation of precursors of the osteoclast-like cells. However, these compounds decreased the proportion of mononuclear and multinucleated cells expressing an osteoclast antigen, thus suggesting a degree of specificity for cells of the osteoclast lineage. We conclude that bisphosphonates are potent inhibitors of osteoclast-like cell formation in long-term human marrow cultures, and that this may be related to their ability to inhibit bone resorption in vivo.
\end{abstract}

\section{Introduction}

The stable pyrophosphate analogues known as bisphosphonates (PCPs, ${ }^{1}$ also designated diphosphonates) are potent inhibitors of bone resorption in vivo and in vitro (reviewed by Fleisch in reference 1) and are established therapeutic agents in Paget's disease of bone (1-7) and hypercalcemia of malignancy (8-10). The precise mechanism of action of these compounds is not understood. It was originally thought that PCPs might

Address correspondence to Dr. D. E. Hughes, Department of Human Metabolism and Clinical Biochemistry, University of Sheffield Medical School, Beech Hill Road, Sheffield S10 2RX, United Kingdom.

Received for publication 22 February 1988 and in revised form 31 January 1989.

1. Abbreviations used in this paper: AHHexBP, 6-amino-1-hydroxyhexylidene-1,1-bisphosphonate; AHPrBP, 3-amino-1-hydroxypropylidene-1,1-bisphosphonate; APAAP, alkaline phosphatase-anti-alkaline phosphatase; $\mathrm{Cl}_{2} \mathrm{MBP}$, dichloromethylene bisphosphonate; GCT-CM, giant cell tumor-conditioned mediùm; HEBP, 1-hydroxethylidene1,1-bisphosphonate; MNC, multinucleated cells; PCP, bisphosphonate; 1,25 D, 1,25-dihydroxyvitamin $\mathrm{D}_{3}$; 3-PHEBP, 3-pyridyl-1-hydroxyethylidene-1,1-bisphosphonate.

J. Clin. Invest.

(C) The American Society for Clinical Investigation, Inc.

0021-9738/89/06/1930/06 \$2.00

Volume 83, June 1989, 1930-1935 inhibit bone resorption through physicochemical effects on hydroxyapatite dissolution (11). More recently it has become clear that PCPs have a wide variety of effects on cells thought to be involved in bone turnover, such as osteoblasts $(12,13)$ and cells belonging to the mononuclear phagocyte system (14-16). However, the relative potencies with which different PCPs inhibit crystal dissolution or cause most of their cellular effects in vitro differ from the relative potencies of these compounds in experimental animals or as therapeutic agents in man. There is some evidence to suggest that PCPs may inhibit the recruitment or differentiation of the osteoclast precursor (17), which is thought to be a mononuclear cell of hematopoietic origin (18-20). We have investigated the effects of PCPs on the formation of multinucleated cells (MNC) in human long-term marrow cultures (described by MacDonald et al., reference 21). Many of the cells formed in these cultures display a number of phenotypic characteristics normally associated with osteoclasts. We have studied the effects of five PCPs on the formation of these cells stimulated by 1,25-dihydroxyvitamin $D_{3}(1,25 \mathrm{D})$ and colony-stimulating factors, and on the expression of an antigen expressed by osteoclasts but not by cells of the mononuclear phagocyte system.

\section{Methods}

Long-term human marrow culture. Human marrow was obtained from sections of rib removed during thoracotomy. The mononuclear fraction was separated by density gradient centrifugation through FicollHypaque (Sigma, Poole, Dorset, UK). These cells were washed and resuspended in MEM-alpha (Gibco, Paisley, Renfrewshire, UK) plus $20 \%$ heat-inactivated horse serum (Gibco). The cells were then added to 16-mm tissue culture wells (Becton Dickinson, Cowley, Oxford, UK) at $5 \times 10^{5}$ cells/well in $0.5 \mathrm{ml}$ medium containing test substances, and were maintained for $3 \mathrm{wk}$ at $37^{\circ} \mathrm{C}$ in a humidified atmosphere of $5 \% \mathrm{CO}_{2}, 95 \%$ air. Media and test substances were partly replenished each week. At the end of this period the cells were fixed with 5\% glutaraldehyde (Sigma) in 0.1 M phosphate buffer ( $\mathrm{pH} 7.2$ ) and stained with Wright's Geimsa stain (Sigma). MNC formation was stimulated either by $10 \mathrm{nM} 1,25 \mathrm{D}$ alone or by first stimulating the proliferation of precursors with giant cell tumor-conditioned medium (GCT-CM; Gibco), a source of colony-stimulating factors $(22,23)$. In the latter experiments, the cells were incubated with $10 \%$ GCT-CM, $10 \mathrm{nM} \mathrm{1,25}$ $\mathrm{D}$, or no stimulus during the first week of culture, and $10 \mathrm{nM} 1,25 \mathrm{D}$ during the second and third weeks. PCPs were made up as $10-\mathrm{mM}$ solutions in PBS (Gibco); the pH was adjusted to 7.4 where necessary and further dilutions were made in culture medium. Unless otherwise mentioned, the PCPs were present during the entire culture period. The following compounds were tested: 3-amino-1-hydroxypropylidene-1,1-bisphosphonate (AHPrBP, formerly APD), dichloromethylene bisphosphonate $\left(\mathrm{Cl}_{2} \mathrm{MBP}\right.$, formerly $\left.\mathrm{Cl}_{2} \mathrm{MDP}\right)$, 1-hydroxethylidene-1,1-bisphosphonate (HEBP, formerly EHDP), 6-amino-1-hydroxyhexylidene-1,1-bisphosphonate (AHHexBP, formerly AHDP), and 3-pyridyl-1-hydroxyethylidene-1,1-bisphosphonate (3-PHEBP). The first four of these have been used clinically and the fifth represents a new group of highly active compounds. HEBP, $\mathrm{Cl}_{2} \mathrm{MBP}, \mathrm{AHHexBP}$, 
and 3-PHEBP were obtained from Norwich Eaton Pharmaceuticals Inc., Norwich, New York; AHPrBP was obtained from the Instituto Gentili, Pisa, Italy. 1,25 D was obtained from Hoffmann-La Roche, Nutley, NJ. MNC formation was measured by counting the total number of cells per well containing three or more nuclei using an inverted stage phase microscope.

Cytotoxicity. The cytotoxicity of the PCPs was assessed in two ways: directly, by trypan blue exclusion after a 24-h incubation; and indirectly, by counting the total number of cells (both mononuclear and multinucleated) adherent after $3 \mathrm{wk}$ in culture. Because of the large number of cells present in each well, a sample of eight serial fields magnified 50 times along the horizontal axis was taken. This sampling pattern was chosen because the distribution of the cells within each well was not random, the MNC in particular being more numerous towards the center of the well. The cell counting technique was chosen because of the necessity to distinguish between mononuclear and multinucleated cells. Such a distinction would not be possible using metabolic studies such as oxygen consumption.

Immunocytochemistry. For immunocytochemical purposes, mononuclear marrow cells were cultured in 6-mm tissue culture wells (Nunc, Roskilde, Denmark) at $10^{5}$ cells/well in $0.2 \mathrm{ml}$ medium. These cultures were maintained for $3 \mathrm{wk}$ as described above, after which they were fixed with $4 \%$ paraformaldehyde, $2 \%$ sucrose in $0.1 \mathrm{M}$ phosphate buffer ( $\mathrm{pH} 7.2)$ at $4^{\circ} \mathrm{C}$ for $30 \mathrm{~min}$. A murine MAb (13 C2) raised against giant-cell tumor osteoclast-like cells (kindly provided by $\mathrm{Dr}$. M. A. Horton, Department of Hematology, St. Bartholomew's Hospital, London, UK) was used to detect the expression of an osteoclast antigen. This MAb does not react with monocytes or macrophages derived from a variety of tissues (24). $13 \mathrm{C} 2$ was added as an undiluted hybridoma tissue culture supernatant for $18 \mathrm{~h}$ at $4^{\circ} \mathrm{C}$. An irrelevant MAb (murine anti-rabbit IgG) was used as a control. Antibody binding was visualized using the alkaline phosphatase-anti-alkaline phosphatase (APAAP) technique (25). Briefly, this technique consists of two stages: after incubation with the primary MAb (i.e., $13 \mathrm{C} 2$ or control), rabbit anti-mouse IgG is added at a high concentration, followed by addition of soluble complexes of calf intestinal alkaline phosphatase (which is resistant to inhibition by levamisole) and murine monoclonal anti-calf intestinal alkaline phosphatase (APAAP complexes). The rabbit anti-mouse IgG binds to both the primary $\mathrm{MAb}$ and to the APAAP complexes, thus forming a link between the two. Naphthol AS-MX phosphate $(0.2 \mathrm{mg} / \mathrm{ml}$; Sigma) was used as a substrate and fast red TR salt ( $1 \mathrm{mg} / \mathrm{ml}$; Sigma) was used to provide an insoluble red reaction product. Levamisole ( $1 \mathrm{M}$; Sigma) was added to the substrate mixture to block endogenous alkaline phosphatase. Hematoxylin was used as a counterstain. Total and $13 \mathrm{C} 2$-positive mononuclear and multinucleated cells were counted using the sampling patterns described for the cytotoxicity and MNC counting experiments, respectively.

Statistics. In the MNC counting and cytotoxicity experiments, means were taken from four replicate wells and significance was assessed by analysis of variance. In the $13 \mathrm{C} 2$ binding experiments, proportions $(p) \pm \mathrm{SE}[\mathrm{SE}(p)]$ were calculated from pooled data from each treatment, according to the formulae

$p=\frac{\text { positive cells }}{\text { total cells }(n)}$, and $\operatorname{SE}(p)=\sqrt{\frac{p(1-p)}{n}}$.

Values of $p$ are expressed as percentages in the results. Significance was assessed by $t$ test. All data shown are representative of at least three experiments.

\section{Results}

All of the five compounds tested inhibited MNC formation stimulated by $10 \mathrm{nM} 1,25 \mathrm{D}$ in a dose-dependent manner at concentrations between $10^{-7}$ and $10^{-4} \mathrm{M}$ (Fig. 1). Using an extended concentration range of $10^{-10}-10^{-4} \mathrm{M}, \mathrm{IC}_{50}$ values were estimated. The data shown in Table I show that although

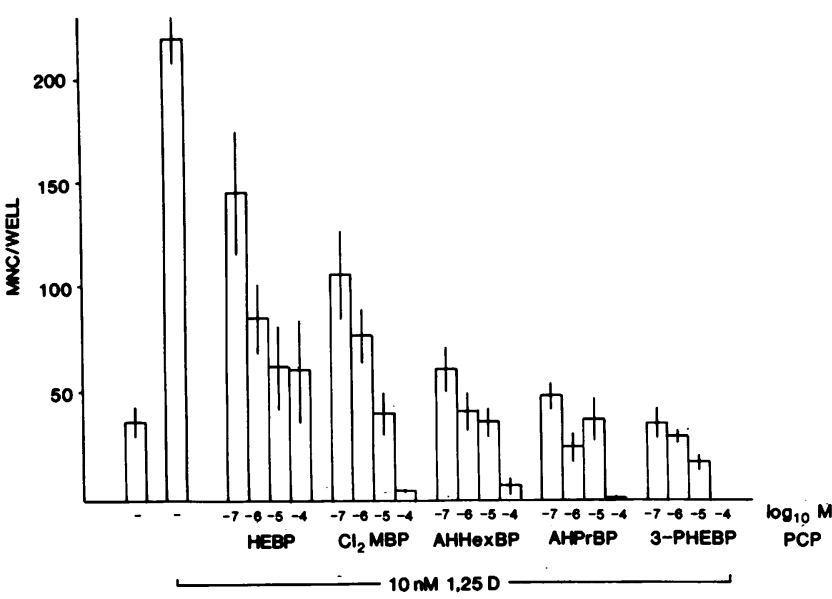

Figure 1. Effects of PCPs on MNC formation in long-term marrow cultures stimulated by $10 \mathrm{nM} 1,25 \mathrm{D}$ : Data shown are mean \pm SEM of four replicates. All concentrations of PCPs show significant inhibition $(P<0.001)$ except $10^{-7} \mathrm{M}$ HEBP.

$\mathrm{IC}_{50}$ values obtained from three experiments varied within an order of magnitude, the relative potencies of the five compounds are the same in each case. The order of potency demonstrated here corresponds exactly to that observed in vivo $(1,26)$.

The possibility that these effects could be due to cytotoxicity of the drugs was investigated by trypan blue exclusion and by assessment of the total number of all cell types remaining in cuilture after 3 wk treatment with the PCPs. There was no evidence of toxicity at concentrations of $10^{-5} \mathrm{M}$ or lower. $10^{-4}$ M AHPrBP, $\mathrm{Cl}_{2} \mathrm{MBP}, \mathrm{AHHexBP}$, and 3-PHEBP caused decreases in viability as assessed by both methods (Table II). This suggests that at this concentration the reductions in MNC number may be partially or wholly due to toxic effects. Shortterm cytotoxicity was also assessed using a biochemical technique that measures numbers of viable cells using a tetrazolium salt (3-(4,5-dimethylthiazol-2-yl)-2,5-diphenyl tetrazolium bromide; reference 27). Using this technique, significant cytotoxicity was only detected in the presence of $10^{-4} \mathrm{M}$ AHHex $\beta$ P (data not shown). This technique, therefore, appeared to be less sensitive than trypan blue exclusion.

AHPrBP and $\mathrm{Cl}_{2} \mathrm{MBP}$ were chosen as representative compounds for the studies on modulation of precursor prolifera-

Table I. Concentrations of PCPs Required To Half-maximally Inhibit the Effect of $10 \mathrm{nM} 1,25 \mathrm{D}$ on MNC Formation

\begin{tabular}{|c|c|c|c|c|c|}
\hline \multirow[b]{2}{*}{ Compound } & \multicolumn{3}{|c|}{$\mathrm{IC}_{50}$} & \multirow[b]{2}{*}{ Mean \pm SEM } & \multirow{2}{*}{$\begin{array}{l}\text { Order o } \\
\text { potency }\end{array}$} \\
\hline & Exp. 1 & Exp. 2 & Exp. 3 & & \\
\hline & & $n M$ & & & \\
\hline HEBP & 6,000 & 29,000 & 40,000 & $25,000 \pm 10,016$ & 5 \\
\hline $\mathrm{Cl}_{2} \mathrm{MBP}$ & 130 & 140 & 650 & $307 \pm 172$ & 4 \\
\hline AHHexBP & 30 & 40 & 120 & $63 \pm 28$ & 3 \\
\hline AHPrBP & 22 & 29 & 80 & $44 \pm 18$ & 2 \\
\hline 3-PHEBP & 4.5 & 1.6 & 11 & $5.7 \pm 2.8$ & 1 \\
\hline
\end{tabular}

The above values were estimated using a concentration range of each compound of $10^{-10}-10^{-4} \mathrm{M}$. Results from three separate experiments are shown. 
Table II. Effects of PCPs on Cell Viability

\begin{tabular}{|c|c|c|c|}
\hline \multicolumn{2}{|c|}{ Treatment } & \multirow{2}{*}{$\begin{array}{l}\text { No. of adherent cells } \\
\text { per well after } 3 \text { wk }\end{array}$} & \multirow{2}{*}{$\begin{array}{l}\text { \% Viable ceils } \\
\text { after } 24 \mathrm{~h}\end{array}$} \\
\hline $1,25 \mathrm{D}(10 \mathrm{nM})$ & PCP & & \\
\hline & $M$ & mean $\pm S E M$ & mean $\pm S E M$ \\
\hline- & - & $263.3 \pm 33.2$ & $98.7 \pm 0.7$ \\
\hline+ & - & $682.0 \pm 51.7$ & $99.3 \pm 0.4$ \\
\hline+ HEBP & $10^{-7}$ & $494.8 \pm 98.3$ & $99.7 \pm 0.3$ \\
\hline+ & $10^{-6}$ & $524.3 \pm 69.7$ & $99.1 \pm 0.4$ \\
\hline+ & $10^{-5}$ & $500.5 \pm 76.0$ & $99.5 \pm 0.5$ \\
\hline+ & $10^{-4}$ & $269.0 \pm 118.6^{\ddagger}$ & $99.7 \pm 0.3$ \\
\hline$+\mathrm{Cl}_{2} \mathrm{MBP}$ & $10^{-7}$ & $563.5 \pm 121.4$ & $99.0 \pm 0.6$ \\
\hline+ & $10^{-6}$ & $620.5 \pm 76.4$ & $99.4 \pm 0.5$ \\
\hline$\dot{+}$ & $10^{-5}$ & $594.5 \pm 105.3$ & $99.7 \pm 0.3$ \\
\hline+ & $10^{-4}$ & $72.0 \pm 16.5^{\S}$ & $97.6 \pm 0.2^{8}$ \\
\hline+ AHHexBP & $10^{-7}$ & $509.5 \pm 23.1$ & $99.0 \pm 0.56$ \\
\hline+ & $10^{-6}$ & $668.0 \pm 130.3$ & $99.4 \pm 0.67$ \\
\hline+ & $10^{-5}$ & $847.5 \pm 149.8$ & $99.3 \pm 0.38$ \\
\hline+ & $10^{-4}$ & $133.3 \pm 27.0^{\S}$ & $96.7 \pm 0.76^{8}$ \\
\hline+ AHPrBP & $10^{-7}$ & $527.5 \pm 55.9$ & $99.0 \pm 0.6$ \\
\hline+ & $10^{-6}$ & $668.8 \pm 100.8$ & $99.1 \pm 0.9$ \\
\hline+ & $10^{-5}$ & $868.8 \pm 195.4$ & $99.7 \pm 0.3$ \\
\hline+ & $10^{-4}$ & $85.0 \pm 11.9^{\S}$ & $96.3 \pm 1.7^{8}$ \\
\hline+ 3-PHEBP & $10^{-7}$ & $618.5 \pm 73.9$ & $99.7 \pm 0.3$ \\
\hline+ & $10^{-6}$ & $529.8 \pm 124.5$ & $99.2 \pm 0.4$ \\
\hline+ & $10^{-5}$ & $815.0 \pm 199.5$ & $98.2 \pm 1.0$ \\
\hline+ & $10^{-4}$ & $0.0 \pm 0.0^{\S}$ & $88.0 \pm 3.6^{8}$ \\
\hline
\end{tabular}

Viability was estimated by numbers of adherent cells present after 3 wk in culture and by trypan blue exclusion after $24 \mathrm{~h}$. The number of adherent cells per well refers not to the total number of cells in each well, but to the number counted using the sampling technique described in Methods.

${ }^{\ddagger} P<0.01 ;{ }^{8} P<0.001$. tion and expression of the antigen recognized by $13 \mathrm{C} 2$, as these compounds have been extensively studied in vivo and in vitro and have potent effects on $\mathrm{MNC}$ formation. Neither $10^{-5}$ M AHPrBP nor $10^{-5} \mathrm{M} \mathrm{Cl}_{2} \mathrm{MBP}$ significantly inhibited the effect of GCT-CM when added during the first week of culture, although AHPrBP significantly inhibited the effect of 1,25 D when present only during this period (Table. III). When the PCPs were present for the entire culture period, MNC formation was inhibited whatever the culture conditions during the first week. These results suggest that precursor proliferation is not the major site of the inhibitory action of PCPs. The data shown in Table III also demonstrate that in order to have their maximal inhibitory effect, the PCPs need to be present for the entire culture period.

The marrow cultures contain a heterogeneous population of both mononuclear and multinucleated cells. A change in the number of MNC may therefore not necessarily reflect a change in osteoclast number. The specificity of the inhibitory effects of PCPs for osteoclast-like rather than non-osteoclastlike MNC (presumably macrophage polykaryons) was assessed by counting the number of cells expressing the osteoclast antigen recognized by the MAb $13 \mathrm{C} 2$. The proportion of $13 \mathrm{C2}-$ positive mononuclear cells was also measured, as changes in the proportion of these cells may indicate an effect on the differentiation of the mononuclear osteoclast precursor. AHPrBP and $\mathrm{Cl}_{2} \mathrm{MBP}$ decreased the numbers of $13 \mathrm{C} 2$-positive $\mathrm{MNC}$ in a dose-dependènt manner (Table IV). In the presence of $10 \mathrm{mM} 1,25 \mathrm{D}, 65.1 \%$ of the MNC and $33.0 \%$ of the mononuclear cells stained positively for $13 \mathrm{C} 2$. Both AHPrBP and $\mathrm{Cl}_{2} \mathrm{MBP}$ decreased the proportion of $13 \mathrm{C2}$-positive mononuclear and multinucleated cells at $10^{-5} \mathrm{M}$, and AHPrBP also had these effects at $10^{-6} \mathrm{M}$ (Fig. 2).

\section{Discussion}

Some of the MNC that form in long-term cultures of human marrow appear to be osteoclasts by several criteria. These cells

Table III. Effects of AHPrBP and $\mathrm{Cl}_{2}$ MBP on GCT-CM-stimulated MNC Precursor Proliferation in Long-term Marrow Cultures

\begin{tabular}{|c|c|c|c|c|c|}
\hline \multicolumn{3}{|c|}{ Treatment during week 1} & \multicolumn{2}{|c|}{ Treatment during weeks 2 and 3} & \multirow[b]{2}{*}{ MNC/well } \\
\hline GCT-CM (10\%) & $1,25 \mathrm{D}(10 \mathrm{nM})$ & $\operatorname{PCP}\left(10^{-5} \mathrm{M}\right)$ & $1,25 \mathrm{D}(10 \mathrm{nM})$ & $\operatorname{PCP}\left(10^{-5} \mathrm{M}\right)$ & \\
\hline & & & & & mean $\pm S E M$ \\
\hline & & & + & & $68.8 \pm 6.5$ \\
\hline & & AHPrBP & + & & $66.0 \pm 6.4$ \\
\hline & & AHPrBP & + & AHPrBP & $24.0 \pm 3.5^{\ddagger}$ \\
\hline & & $\mathrm{Cl}_{2} \mathrm{MBP}$ & + & & $59.8 \pm 7.6$ \\
\hline & & $\mathrm{Cl}_{2} \mathrm{MBP}$ & + & $\mathrm{Cl}_{2} \mathrm{MBP}$ & $36.3 \pm 6.8^{*}$ \\
\hline+ & & & + & & $339.3 \pm 48.5$ \\
\hline+ & & AHPrBP & + & & $284.3 \pm 12.9$ \\
\hline+ & & AHPrBP & + & AHPrBP & $43.8 \pm 11.0^{8}$ \\
\hline+ & & $\mathrm{Cl}_{2} \mathrm{MBP}$ & + & & $304.8 \pm 39.3$ \\
\hline \multirow[t]{6}{*}{+} & & $\mathrm{Cl}_{2} \mathrm{MBP}$ & + & $\mathrm{Cl}_{2} \mathrm{MBP}$ & $53.0 \pm 14.3^{8}$ \\
\hline & + & & + & & $197.0 \pm 14.9$ \\
\hline & + & AHPrBP & + & & $114.8 \pm 18.9^{*}$ \\
\hline & + & AHPrBP & + & AHPrBP & $48.8 \pm 5.4^{8}$ \\
\hline & + & $\mathrm{Cl}_{2} \mathrm{MBP}$ & + & & $148: 3 \pm 18.9$ \\
\hline & + & $\mathrm{Cl}_{2} \mathrm{MBP}$ & + & $\mathrm{Cl}_{2} \mathrm{MBP}$ & $69.4 \pm 13.9^{8}$ \\
\hline
\end{tabular}

Data shown are mean \pm SEM of four replicates. * Significantly different from appropriate control $(P<0.05)$. ${ }^{\ddagger}$ Significantly different from appropriate control $(P<0.01)$. ${ }^{8}$ Significantly different from appropriate control $(P<0.001)$. 
Table IV. Effects of $A H P r B P$ and $\mathrm{Cl}_{2} \mathrm{MBP}$ on the Expression of the Osteoclast Antigen Recognized by the MAb $13 C 2$

\begin{tabular}{ccccc}
\hline \multicolumn{2}{c}{ Treatment } & & & \\
\hline $1,25 \mathrm{D}(10 \mathrm{nM})$ & PCP & No. of 13 C2-positive cells & Total cells \\
\hline & $M$ & Mean $\pm S E M$ & Mean $\pm S E M$ \\
Mononuclear cells & & & \\
- & - & $17.0 \pm 1.4$ & $81.8 \pm 12.4$ \\
+ & - & $21.8 \pm 1.8$ & $64.8 \pm 8.4$ \\
+ & AHPrBP & $10^{-7}$ & $28.7 \pm 5.1$ & $78.5 \pm 11.4$ \\
+ & $10^{-6}$ & $24.8 \pm 4.6$ & $100.3 \pm 13.2$ \\
+ & $10^{-5}$ & $21.6 \pm 4.6$ & $102.5 \pm 7.2^{*}$ \\
+ & & $25.2 \pm 3.8$ & $75.3 \pm 12.0$ \\
+ & $10^{-7}$ & $24.0 \pm 6.1$ & $78.2 \pm 21.9$ \\
& $10^{-6}$ & $23.5 \pm 5.4$ & $93.2 \pm 9.4$
\end{tabular}

MNC

$\begin{array}{lccc}- & - & 5.0 \pm 0.0 & 11.0 \pm 1.0 \\ + & - & 85.0 \pm 10.0 & 130.5 \pm 18.5 \\ + \text { AHPrBP } & 10^{-7} & 46.5 \pm 4.5^{\ddagger} & 85.0 \pm 9.0 \\ + & 10^{-6} & 32.0 \pm 3.0^{\ddagger} & 61.0 \pm 12.0^{\ddagger} \\ + & 10^{-5} & 22.5 \pm 10.5^{\S} & 48.5 \pm 8.5^{\ddagger} \\ +\mathrm{Cl}_{2} \mathrm{MBP} & 10^{-7} & 56.0 \pm 1.0^{*} & 91.5 \pm 10.5 \\ + & 10^{-6} & 38.0 \pm 9.0^{\ddagger} & 68.5 \pm 22.5^{*} \\ + & 10^{-5} & 24.0 \pm 5.0^{\S} & 47.5 \pm 13.5^{\ddagger}\end{array}$

"No. 13 C2-positive cells" and "Total cells" refer to mean \pm SEM per field using the sampling pattern described in Methods for the cytotoxicity experiments for the mononuclear cells (eight fields each from duplicate wells) or mean \pm SEM per well for the MNC (using the same duplicate wells). The values obtained by calculating the percentages of mononuclear and multinucleated cells reacting with the $13 \mathrm{C} 2 \mathrm{MAb}$ for each particular treatment in this experiment are shown in Fig. 2.

* Significantly different from appropriate 1,25 D-treated control, $P$ $<0.05$.

¥ Significantly different from appropriate 1,25 D-treated control, $P$ $<0.01$.

${ }^{\S}$ Significantly different from appropriate 1,25 D-treated control, $P$ $<0.001$.

have the biochemical characteristics of osteoclasts in that they express a number of osteoclast-specific antigens and the enzyme tartrate-resistant acid phosphatase which is generally considered to be osteoclast-specific in vivo. Secondly, they are morphologically similar to osteoclasts under transmission electron microscopy and have been shown in this and other laboratories to form resorption pits in devitalized bone $(21,28$, $29)$. Finally, they respond to stimulators $(21,30)$ and inhibitors $(21,31)$ of bone resorption with appropriate increases or decreases in MNC numbers. Indeed, all stimulators of bone resorption so far tested in this system, including the cytokines tumor necrosis factor and IL-1 (unpublished results) have increased MNC numbers. This study provides further evidence for this by showing that PCPs, which are potent inhibitors of bone resorption, also inhibit MNC formation.

We have shown that five PCPs all inhibited the formation of MNC in long-term human marrow cultures stimulated by 1,25 D. 1,25 D was chosen because it consistently stimulates
MNC formation in long-term marrow cultures and is a wellrecognized stimulator of bone resorption. The potencies of these compounds in this system were greater than in any in vitro system reported to date. Furthermore, the relative potencies in vivo of the four of these compounds that have been used therapeutically (AHPrBP $>$ AHHexBP $>\mathrm{Cl}_{2} \mathrm{MBP}>\mathrm{HEBP}$, references 1 and 26) are the same as observed in our studies. 3-PHEBP has not been used in humans, but is more potent than the other compounds in animal models (32). Given that five compounds could have 120 different orders of potency, the probability of the same order occurring by chance in three experiments is 1 in $120^{3}$ or $6 \times 10^{-7}$. The inhibition of MNC formation shown in these experiments may therefore be the major action of PCPs in vivo.

The inhibitory effect of AHPrBP and $\mathrm{Cl}_{2} \mathrm{MBP}$ on the expression by $\mathrm{MNC}$ of the antigen recognized by $13 \mathrm{C} 2$ suggests that PCPs inhibit the formation of osteoclast-like MNC more strongly than they inhibit the formation of non-osteoclast-like MNC. Although $13 \mathrm{C} 2$ also reacts with renal proximal tubule cells and glomerular viscera, it can be considered as osteoclast-specific in the context of bone marrow cultures, as it does not react with other hematopoietic cells (24). This MAb also inhibits the resorption of devitalized bone by isolated osteoclasts (33), thus suggesting that it binds to an important functional site on the osteoclast. The identity of the mononuclear cells that react with $13 \mathrm{C} 2$ is uncertain, but as neither monocytes nor bone marrow-derived macrophages react with this antibody, these cells are probably closely related to the osteoclast, possibly being precursors. Fuller and Chambers (34) have shown that when cultures of rabbit bone marrow are grown on devitalized bone, the presence of resorption pits detected by scanning electron microscopy correlates with the presence of mononuclear cells or cells of low multinuclearity reacting with another anti-osteoclast monoclonal $(23 \mathrm{C} 6)$ in parallel cultures. This MAb like $13 \mathrm{C} 2$, was raised by Dr. M. A. Horton against giant cell tumor osteoclast-like cells, and reacts with the same protein as $13 \mathrm{C} 2$ (35). Furthermore, expression of tartrate-resistant acid phosphatase by mononuclear cells has

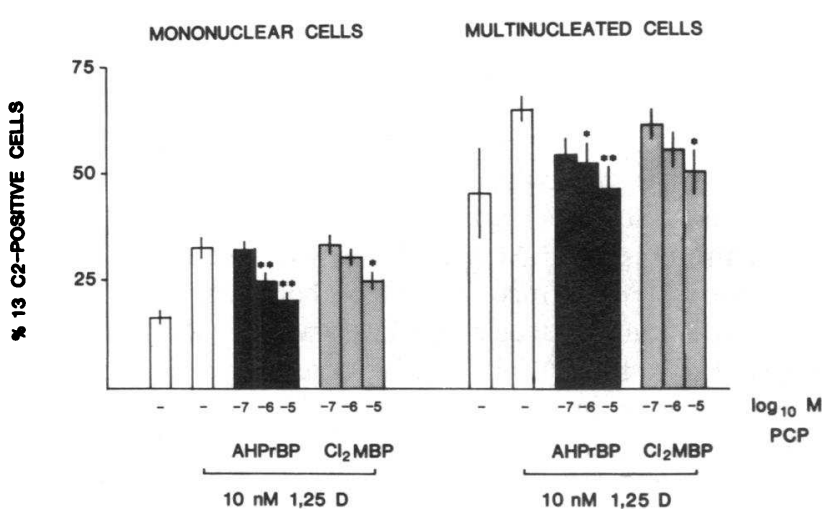

Figure 2. Effects of AHPrBP and $\mathrm{Cl}_{2} \mathrm{MBP}$ on expression of the osteoclast antigen recognized by the MAb $13 \mathrm{C} 2$. Data shown are percentage of cells staining positively for $13 \mathrm{C} 2 \pm$ SEM from samples taken as described in Methods, calculated as total $13 \mathrm{C} 2$-positive cells divided by total cells counted $\times 100 \%$, from the data shown in Table II. *Significantly different from appropriate 1,25 D-treated control, $P$ $<0.05$. ${ }^{* *}$ Significantly different from appropriate 1,25 D-treated control, $P<0.01$. 
been demonstrated both in the marrow culture system described here (21) and on bone surfaces in vivo immediately before the appearance of osteoclasts in the bone remodeling sequence (36). These observations support the concept that the osteoclast precursor may express features of the osteoclast phenotype during the later stages of its differentiation, and that such cells may be present in long-term marrow cultures. Furthermore, recent studies suggest that the protein with which 13 $\mathrm{C} 2$ reacts is a receptor for a matrix protein (35). It is generally believed that mononuclear osteoclast precursors attach themselves to the bone surface before fusing (36) and it would therefore seem likely that these cells express such receptors. Addition of $1,25 \mathrm{D}$, which is a potent differentiating agent in other cell systems, increased the proportion of mononuclear and multinucleated cells expressing the $13 \mathrm{C} 2$ antigen. However, this effect was abolished by simultaneous addition of PCPs. The decrease in the proportion of $13 \mathrm{C} 2$-positive mononuclear cells observed in the presence of PCPs may therefore indicate that these compounds inhibit the differentiation of osteoclast precursors. This observation also suggests that PCPs do not simply inhibit fusion of osteoclast precursors, because if this were the case, increased numbers of $13 \mathrm{C} 2$-positive mononuclear cells would be expected in PCP-treated cultures. A more precise interpretation of these results requires a better understanding of the identity of the various cell populations present in long-term marrow cultures.

Transforming growth factor-alpha and epidermal growth factor stimulate the formation of $\mathrm{MNC}$ in these cultures through enhanced precursor proliferation (30). Granulocytemacrophage colony-stimulating factor and macrophage colony-stimulating factor, both of which are present in GCT-CM, have also been shown to have this effect in long-term cultures of baboon marrow (37). Neither AHPrBP nor $\mathrm{Cl}_{2} \mathrm{MBP}$ significantly inhibited GCT-CM-stimulated precursor proliferation during the first week of culture. This might appear to contradict the findings of Cecchini et al. (38) who observed that three PCPs, including AHPrBP and $\mathrm{Cl}_{2} \mathrm{MBP}$, inhibited granulocytemacrophage and macrophage colony-stimulating factor-stimulated colony formation in murine marrow cultures. However, these effects may be overcome in long-term cultures, and probably do not occur to a significant extent in vivo, as suppression of myelopoiesis has very rarely been reported in PCP-treated patients. Studies by Boonekamp et al. $(17,39)$ using organ culture systems have suggested that PCPs have two modes of action on osteoclastic bone resorption, inhibiting both the accession (migration to the bone surface and fusion) of osteoclast precursors and resorption by the mature osteoclast. Higher concentrations $\left(10^{-5} \mathrm{M}\right.$ and above) were required to inhibit resorption by preformed osteoclasts than were required to inhibit accession of osteoclast precursors $\left(10^{-6} \mathrm{M}\right.$ and above, in the case of AHPrBP). The relative potencies of the three compounds tested in these systems (AHPrBP, $\mathrm{Cl}_{2} \mathrm{MBP}$, and $\mathrm{HEBP}$ ) also differed; $\mathrm{Cl}_{2} \mathrm{MBP}$ inhibited resorption by mature osteoclasts most strongly, whereas the relative potencies of these three compounds in inhibiting osteoclast precursor accession were the same as those seen in our studies. It would therefore appear that although they are capable of acting directly on adult osteoclasts, PCPs inhibit bone resorption primarily by an effect on the formation of osteoclasts that appears to be at the level of the postmitotic precursor.

Long-term marrow culture may, therefore, prove to be a useful ex vivo technique for studying the efficacy of new thera- peutic agents and the mechanism of action of existing ones. Bisphosphonates are potentially the most efficacious therapeutic agents for treating diseases of increased bone turnover such as Paget's disease and many cases of hypercalcemia of malignancy. Furthermore, PCPs may prove to have applications in other diseases of bone and mineral metabolism such as hyperparathyroidism (7) and certain forms of osteoporosis (40). It has been shown in a single case that bone marrow taken from a patient with hyperparathyroidism formed $\mathrm{MNC}$ in greater numbers than normal controls and that this effect was reversed after parathyroidectomy (21). The ability to study MNC formation in disease states illustrates the usefulness of this system for the study of the pathophysiological and pharmacological control of bone resorption. Unfortunately, the first PCP available for general use, etidronate (HEBP), causes mineralization defects during long-term administration $(3,41)$ and therefore should in time be replaced by more potent compounds (such as $\mathrm{AHPrBP}, \mathrm{Cl}_{2} \mathrm{MBP}$, or $\mathrm{AHHexBP}$ ) that lack this side effect at therapeutic doses. Other new, highly potent PCPs, for example 3-PHEBP, are currently being studied. Long-term marrow cultures may prove to be a valuable screening technique for these compounds.

\section{Acknowledgments}

We would like to thank Dr. M. A. Horton, Senior Lecturer in Hematology, St. Bartholomew's Hospital, London, for kindly providing the $13 \mathrm{C} 2 \mathrm{MAb}$ and for helpful discussions. We would also like to thank the cardiothoracic surgeons and the theater staff at the Northern General Hospital, Sheffield, for their help in providing tissue.

M. Gowen is the holder of a Royal Society 1983 University Research Fellowship and D. Hughes was the recipient of a studentship from the Science and Engineering Research Council.

\section{References}

1. Fleisch, H. 1982. Bisphosphonates: mechanisms of action and clinical applications. In Bone and Mineral Research Annual 1. W. A. Peck, editor. Excerpta Medica, Amsterdam. 319-357.

2. Altman, R. D., C. C. Johnston, M. R. R. A. Khairi, H. Wellman, A. N. Scrafini, and R. R. Sankey. 1973. Influence of sodium etidronate on clinical and laboratory manifestations of Paget's disease of bone (osteitis deformans). N. Engl. J. Med. 289:1379-1384.

3. Russell, R. G. G., R. Smith, C. J. Preston, R. S. Walton, and C. G. Woods. 1974. Diphosphonates in Paget's disease. Lancet. i:894898.

4. Canfield, R., W. Rosner, J. Skinner, J. McWhorter, L. Resnick, F. Feldman, S. Kammermans, J. Ryan, M. Kunigonis, and W. Bohne. 1977. Diphosphonate therapy of Paget's disease of bone. J. Clin. Endocrinol. Metab. 44:96-106.

5. Khairi, M. R. A., R. D. Altman, G. P. De Ross, J. Zimmerman, R. K. Schenk, and C. C. Johnston. 1977. Sodium etidronate in the treatment of Paget's disease of bone. Ann. Int. Med. 87:656-663.

6. Frijlink, W. B., O. L. M. Bijvoet, J. Te Velde, and G. Heynen. 1979. Treatment of Paget's disease of bone with (3-amino-1-hydroxypropylidene)-1,1-bisphosphonate (A.P.D.) Lancet. i:799-803.

7. Douglas, D. L., T. Duckworth, R. G. G. Russell, J. A. Kanis, C. J. Preston, F. E. Preston, M. A. Prenton, and J. S. Woodhead. 1980. Effect of dichloromethylene diphosphonate in Paget's disease of bone and hypercalcaemia due to primary hyperparathyroidism or malignant disease. Lancet. i:1043-1047.

8. Sleeboom, H. P., O. L. M. Bijvoet, A. J. van Oosteron, J. H. Gleed, and J. L. H. O'Riordan. 1983. Comparison of intravenous (3-amino-1-hydroxypropylidene)-1,1-bisphosphonate and volume repletion in tumour-induced hypercalcaemia. Lancet. i:239-243. 
9. Percival, R. C., A. D. Paterson, A. J. P. Yates, D. J. Beard, D. L. Douglas, F. E. Neal, R. G. G. Russell, and J. A. Kanis. 1985. Treatment of malignant hypercalcaemia with clodronate. Br. J. Cancer. 51:665-669.

10. Ralston, S. J., M. D. Gardner, F. J. Dryborough, A. S. Jenkins, R. A. Cowan, and I. T. Boyle. 1985. Comparison of aminohydroxypropylidene diphosphonate, mithramycin and corticosteroids/calcitonin in treatment of cancer-associated hypercalcaemia. Lancet. ii:907-910.

11. Russell, R. G. G. 1975. Diphosphonates and polyphosphates in medicine. Br. J. Hosp. Med. 14:297-314.

12. Ohya, K., S. Yamada, R. Felix, and H. Fleisch. 1985. Effect of bisphosphonates on prostaglandin synthesis by rat bone cells and mouse calvaria in culture. Clin. Sci. (Lond.). 69:403-411.

13. Fast, D. K., R. Felix, C. Dose, W. F. Neuman, and H. Fleisch. 1978. The effects of diphosphonates on the growth and glycolysis of connective tissue cells in culture. Biochem. J. 172:97-107.

14. Bijvoet, O. L. M., W. B. Frijlink, K. Jie, H. van der Linden, C. J. L. M. Meijer, H. Mulder, H. C. van Paasen, P. J. Reitsma, J. te Velde, E. de Vries, and J. P. van der Wey. APD in Paget's disease of bone: role of the mononuclear phagocyte system? Arthritis Rheum. 23:1193-1204.

15. Stevenson, P. H., and J. R. Stevenson. 1986. Cytotoxic and migration inhibitory effects of bisphosphonates on macrophages. $\mathrm{Cal}$ cif. Tissue Int. 38:227-233.

16. Reitsma, P. H., S. L. Teitelbaum, O. L. M. Bijvoet, and A. J. Khan. 1982. Differential actions of the bisphosphonates APD and $\mathrm{Cl}_{2} \mathrm{MDP}$ on macrophage-mediated bone resorption in vitro. J. Clin. Invest. 70:927-933.

17. Boonekamp, P. M., L. J. A. van der Wee-Pals, M. M. L. van Wijk-van Lennep, C. W. Thesing, and O. L. M. Bijvoet. 1986. Two modes of action of bisphosphonates on osteoclastic resorption of mineralized matrix. Bone Miner. 1:27-39.

18. Fishman, D. A., and E. D. Hay. 1962. Origin of osteoclasts from mononuclear leukocytes in regenerating newt limbs. Anat. Rec. 143:329-334.

19. Kahn, A. J., and D. J. Simmons. 1975. Investigation of cell lineage in bone using chimera of chick and quail embryonic tissue. Nature (Lond.). 258:323-327.

20. Ash, P., J. F. Loutit, and K. M. S. Townsend. 1980. Osteoclasts derived from haematopoietic stem cells. Nature (Lond.). 283:669-670.

21. MacDonald, B. R., N. Takahashi, L. M. McManus, J. Holahan, G. R. Mundy, and G. D. Roodman. 1987. Formation of multinucleated cells that respond to osteotropic hormones in long-term human bone marrow cultures. Endocrinology. 130:2326-2333.

22. Dispersio, J. F., K. J. Brennan, M. A. Lichtman, and B. L. Speiser. 1978. Human cell lines that elaborate colony-stimulating activity for the marrow cells of man and other species. Blood. 51:507519.

23. Das, S. K., E. R. Stanley, L. J. Guilbert, and L. W. Forman. 1981. Human colony-stimulating factor (CSF-1) radioimmunoassay: resolution of three subclasses of human colony-stimulating factors. Blood. 58:630-641.

24. Horton, M. A., D. Lewis, J. McNulty, J. A. S. Pringle, and T. J. Chambers. 1985. Monoclonal antibodies to osteoclastomas (giant cell bone tumours): definition of osteoclast-specific cellular antigens. Cancer Res. 45:5663-5669.

25. Cordelli, J. L., B. Falini, W. N. Fober, A. K. Ghosh, Z. Abdulaziz, S. MacDonald, K. A. F. Pulford, H. Stein, and D. Y. Mason. 1984. Immunoenzymatic labelling of monoclonal antibodies using immune complexes of alkaline phosphatase and monoclonal anti-al- kaline phosphatase (APAAP complexes). J. Histochem. Cytochem. 32:219-229.

26. Adami, S., G. Salvagno, R. Dorizzi, F. Bertoldo, and V. Lo Cascio. 1985. The acute phase response after administration of bisphosphonates in humans. Calcif. Tissue Int. 38:S21. (Abstr.)

27. Mossman, T. 1983. Rapid colorimetric assay for cellular growth and survival: application to proliferation and cytotoxicity assays. J. Immunol. Methods. 65:55-63.

28. Roodman, G. D., N. Takahashi, G. R. Mundy, S. J. Jones, and A. Boyde. 1987. Human marrow-derived multinucleated cells form resorption lacunae on sperm whale dentine. J. Bone Miner. Res. 2:S1,375. (Abstr.)

29. Thavarajah, M., D. B. Evans, M. A. Horton, and J. A. Kanis. 1987. Human osteoclasts induced by marrow culture resorb bone. J. Bone Miner. Res. 2:S1, 371. (Abstr.)

30. Takahashi, N., B. R. MacDonald, J. Hon, M. E. Winkler, R. Derynck, G. R. Mundy, and G. D. Roodman. 1986. Recombinant human transforming growth factor alpha stimulates the formation of osteoclast-like cells in long-term human marrow cultures. J. Clin. Invest. 78:894-898.

31. Takahashi, N., G. R. Mundy, and G. D. Roodman. 1986. Recombinant human interferon- $\gamma$ inhibits formation of human osteoclast-like cells. J. Immunol. 137:3544-3549.

32. Benedict, J. J., K. Y. Johnston, J. S. Bevan, and C. M. Perkins. 1985. A structure/activity study of nitrogen heterocycle containing bis(phosphonates) as bone resorption inhibiting agents. Calcif. Tissue Int. 38:S31. (Abstr.)

33. Chambers, T. J., K. Fuller, J. A. Darby, J. A. S. Pringle, and M. A. Horton. 1986. Monoclonal antibodies against osteoclasts inhibit bone resorption in vitro. Bone Miner. 1:127-135.

34. Fuller, K., and T. J. Chambers. 1987. Generation of osteoclasts in cultures of rabbit bone marrow and spleen cells. J. Cell. Physiol. 132:441-452.

35. Davies, J., and M. A. Horton. 1988. Osteoclasts express a second adhesion receptor: immunolocalisation of VLA antigens. Calcif. Tissue Int. 42(Suppl):A5. (Abstr.)

36. Baron, R., L. Neff, P. T. Van, J. R. Nefussi, and A. Vignery. 1986. Kinetic and cytochemical identification of osteoclast precursors and their differentiation into multinucleated osteoclasts. Am. J. Pathol. 121:363-378.

37. MacDonald, B. R., G. R. Mundy, S. Clark, E. A. Wang, T. J. Kuehl, E. R. Stanley, and G. D. Roodman. 1986. Effects of human recombinant CSF-GM and highly purified CSF-1 on the formation of multinucleated cells with osteoclast characteristics in long-term bone marrow cultures. J. Bone Miner. Res. 2:227-233.

38. Cecchini, M. G., R. Felix, H. Fleisch, and P. H. Cooper. 1987. Effect of bisphosphonates on proliferation and viability of mouse bone marrow-derived macrophages. J. Bone Miner. Res. 2:135-142.

39. Boonekamp, P. M., C. W. G. M. Lowik, L. J. A. van der Wee-Pals, M. L. L. van Wijk-van Lennep, and O. L. M. Bijvoet. 1987. Enhancement of the inhibitory action of APD on the transformation of osteoclast precursors into resorbing cells after dimethylation of the amino group. Bone Miner. 2:29-42.

40. Minaire, P., E. Berard, P. J. Meunier, C. Edouard, G. Goedert, and G. Pilonchery. 1981. Effects of disodium dichloromethylene diphosphonate on bone loss in paraplegic patients. J. Clin. Invest. 68:1086-1092.

41. De Vries, H. R., and O. L. M. Bijvoet. 1974. Results of prolonged treatment of Paget's disease of bone with ethane-1-hydroxy1,1-diphosphonate (EHDP). Neth. J. Med. 17:281-298. 